\title{
BMJ Open Student perspectives on barriers to performance for black and minority ethnic graduate-entry medical students: a qualitative study in a West Midlands medical school
}

\author{
Nariell Morrison (D), Michelle Machado, Clare Blackburn
}

To cite: Morrison $\mathrm{N}$,

Machado M, Blackburn C. Student perspectives on barriers to performance for black and minority ethnic graduate-entry medical students: a qualitative study in a West Midlands medical school. BMJ Open 2019;9:e032493. doi:10.1136/ bmjopen-2019-032493

- Prepublication history for this paper is available online. To view these files, please visit the journal online (http://dx.doi org/10.1136/bmjopen-2019032493).

Received 20 June 2019 Revised 25 October 2019 Accepted 05 November 2019

Check for updates

(C) Author(s) (or their employer(s)) 2019. Re-use permitted under CC BY-NC. No commercial re-use. See rights and permissions. Published by BMJ.

Division of Health Sciences, Warwick Medical School, University of Warwick, Coventry, UK

Correspondence to

Nariell Morrison;

n.morrison@warwick.ac.uk

\section{ABSTRACT}

Objective To explore graduate-entry medical students experiences of undergraduate training in the context of academic underperformance of medical students from ethnic minority backgrounds.

Design Qualitative study using semi-structured focus groups.

Setting A West Midlands medical school.

Participants 24 graduate-entry MBChB students were recruited using volunteer and snowball sampling; all students self-identified as being from Black and Minority Ethnic (BME) backgrounds.

Results BME students reported facing a range of difficulties, throughout their undergraduate medical training, that they felt impeded their learning and performance. Their relationships with staff and clinicians, though also identified as facilitators to learning, were also perceived to have hindered progress, as many students felt that a lack of BME representation and lack of understanding of cultural differences among staff impacted their experience. Students also reported a lack of trust in the institution's ability to support BME students, with many not seeking support. Students' narratives indicated that they had to mask their identity to fit in among their peers and to avoid negative stereotyping. Although rare, students faced overt racism from their peers and from patients. Many students reported feelings of isolation, reduced self-confidence and low self-esteem.

Conclusions BME students in this study reported experiencing relationship issues with other students, academic and clinical staff, lack of trust in the institution and some racist events. Although it is not clear from this small study of one institution whether these findings would be replicated in other institutions, they nevertheless highlight important issues to be considered by the institution concerned and other institutions. These findings suggest that all stakeholders of graduate-entry undergraduate medical education should reflect on the current institutional practices intended to improve student-peer and student-staff relationships. Reviewing current proposals intended to diversify student and staff populations as well as evaluating guidance on tackling racism is likely to be beneficial.
Strengths and limitations of this study

- This is the first study to explore graduate-entry BME medical students' experiences of medical education; providing valuable insights into the causes of differential attainment by ethnicity in medical assessments.

- This study has a small sample but multiple cohorts participated in this study, broadening the scope of narrated experiences and the variety of views.

- The focus group methodology allowed candid responses and group discussion facilitated recollection of experiences but some participants may have felt inhibited to share personal experiences and therefore some sensitive topics may have been underdiscussed.

- It must be taken into consideration that the emergent themes from the data were dependent on the chosen sample; other themes may have arisen if different or more participants had taken part in the study.

\section{INTRODUCTION}

In higher education, students from Black and Minority Ethnic (BME) backgrounds in the UK have been reported to underperform academically compared with their white counterparts. ${ }^{1}$ Medicine is no different; a number of studies in the UK have reported underperformance at undergraduate and postgraduate levels by BME medical students and trained doctors. ${ }^{2-4}$ Similar findings have been reported in the $\mathrm{USA}^{5}$ and the Netherlands. ${ }^{6}$ This persistent difference in performance between ethnic groups is known as the differential attainment gap and poses a huge issue for medical education and the medical profession. Evidence suggests that this attainment gap exists throughout various undergraduate and postgraduate medical assessments including machinemarked written examinations and objective 
structured clinical examinations. ${ }^{2478}$ Although the differential attainment gap has been widely documented, the reasons for it remain unclear. ${ }^{2910}$

Current literature findings suggest that ethnic stereotypes may contribute to BME medical students' underperformance, yet overt discrimination has not been evidenced. ${ }^{11}$ Furthermore, a longitudinal study and analysis of UK medical students concluded that the ethnic differences in performance were not due to psychological or demographic factors. ${ }^{3}$ A 2017 independent review panel at Cardiff University also highlighted that BME medical students have a different student experience to their white counterparts. ${ }^{12}$ The lack of BME staff within medical schools; difficulty in 'fitting in' and racial stereotyping have all emerged as themes experienced by BME students. ${ }^{11} 12$

Previous studies ${ }^{2-4}$ have focused on undergraduate medical students on five or 6-year programmes. To the best of our knowledge, no published studies have specifically explored the potential causes of the differential attainment gap in graduate-entry medicine (GEM). The UK introduction of 4-year GEM courses began in 2000, following the 1997 UK Medical Workforce Standing Advisory Committee recommendation to diversify the medical student population. ${ }^{13}$ As GEM currently accounts for approximately $10 \%$ of all UK medical programmes ${ }^{13}$ it is important to report the differential attainment gap among GEM courses and examine the experiences of BME graduate-entry medical students as part of a portfolio of research into differential attainment among medical students.

This paper reports data on a study of graduate-entry medical students in a West Midlands medical school. Internal $\mathrm{MBChB}$ assessment data ${ }^{14}$ suggests that for students in this medical school, over the last 4 years across all assessment formats, all cohorts at some point show statistically significant differences in attainment between BME and white students, with BME students having lower average percentage point scores than white students. This study therefore aims to build on previous research, examining the potential reasons for underperformance by BME graduate-entry medical students, exploring their experiences of undergraduate medical training and their perceptions of barriers and facilitators to performance.

\section{METHODS \\ Design}

A social constructivist ${ }^{15}$ approach using qualitative methods was adopted to gain an understanding of medical students' experiences and their perspectives on barriers to performance. Data were gathered in focus groups throughout November 2018, using a semi-structured interview schedule. Two encrypted audio recorders were utilised for data capture. Focus group participants received a maximum of two emails including one email reminder.

\section{Sampling strategy and recruitment}

The sampling frame was all students in each of the four cohorts of the MBChB course at a West Midlands Medical School; all chosen because of their varying experience of medical training as well as academic examinations. The sampling frame was used to recruit participants who selfidentified as BME. This group encompassed but was not limited to, those who identified as being from African, Asian, Arab or Caribbean descent. Participants were eligible to participate if they were either in the clinical phases of the MBChB (years 2-4) or resitting the preclinical phase of training (year 1). Other year 1 students were excluded from participating as they had only been on the course for 2 months and therefore had limited experience of the MBChB course.

Participants were recruited in four main ways: administrative staff emailed invitations to all medical students asking for eligible volunteers to register their interest to participate; invitations to express interest in taking part were posted on the official University MBChB Facebook cohort group pages; participants in the early focus groups encouraged other eligible students to register their interest to participate; and participants were encouraged to bring any eligible students with them on the day. All students with an interest in the study were provided with a participation information leaflet and a consent form. Twenty-six students registered interest and accepted the invitation to participate. Four focus groups, each of 4-7 multicohort students, were then scheduled throughout November 2018, based on participant availability. Focus groups took place in a private room at the University. Owing to last-minute timetable changes, two volunteers were unable to attend any of the focus group sessions.

\section{Ethical approval}

The study involved the collection and analysis of the special category of ethnicity. To ensure confidentiality, data security and compliance with the General Data Protection Regulations, all data were anonymised and held only by NM. All participants confirmed on their consent form that they agreed to keep confidential the identities of focus group participants and to maintain the confidentiality of the information discussed during the focus group.

\section{Data collection methods}

NM (black British, female, graduate-entry undergraduate medical student with quantitative and qualitative research methods training) moderated each focus group. At each group, participants were randomly assigned a number to ease anonymisation during transcription. Participants were subsequently asked to self-report their ethnicity using the 2011 UK census categories. ${ }^{16}$

Many participants were acquainted with each other through enrolment on the MBChB course. At the outset of each focus group, participants were briefed on the purpose of each group, thus creating a comfortable, 
Table 1 Braun and Clarke's six-phase framework for doing a thematic analysis

\begin{tabular}{ll}
\hline Step 1 & Become familiar with the data \\
Step 2 & Generate initial codes \\
Step 3 & Search for themes \\
Step 4 & Review themes \\
Step 5 & Define themes \\
Step 6 & Write-up \\
\hline
\end{tabular}

permissive environment, encouraging participants to talk freely. $^{17}$

Throughout the discussion, first-hand narratives were encouraged and participants were prompted to clarify and expand their answers. Participants were encouraged to respond to others' contributions and discuss similar or contrasting accounts if appropriate. Focus groups ranged from 60 minutes to 3 hours (average $111 \mathrm{~min}$ ).

No attempt was made to exclude friends, with the aim that some collective recollection of events may be captured and on the basis that participants would be more likely to raise sensitive topics if accompanied by friends. ${ }^{17}$

\section{Data processing and analysis}

Data were audio-recorded and transcribed verbatim using Microsoft Word and Olympus Sonority V.1.4.7.

Thematic analysis ${ }^{18}$ was adopted using Braun and Clarke's six-phase framework, shown in table $1 .{ }^{19} \mathrm{NM}$, MM (Associate Professor in Health Sciences) and CB (Associate Professor in Health Sciences) read all transcripts individually to allow/increase familiarisation with the data. QSR NVivo V.12 ${ }^{20}$ software was used to assist with categorisation and management of the data. Following a thorough review of all transcripts, inductive codes were generated and agreed upon by the team. A number of themes were identified from the coded data. The team discussed the findings and collectively agreed on an initial coding framework. NM coded the first three transcripts independently using the initial coding framework, which was then refined after further discussion. Following further review, a final coding framework was adopted, which was subsequently used to code the entire data set. The Standards for Reporting Qualitative Research (SRQR) guidelines were adopted. ${ }^{21}$

\section{Patient and public involvement}

This research was done without patient involvement. Patients were not invited to comment on the study design and were not consulted to interpret the results. Patients were not invited to contribute to the writing or editing of this document for readability or accuracy.

\section{RESULTS}

\section{Participants}

Twenty-four medical students participated in the study. Participant demographics are shown in figure 1.
Participants held a minimum of an upper second-class honours undergraduate degree (or overseas equivalent). Any participant with a lower second-class undergraduate degree held either a Master's or a Doctoral qualification. Twenty-three out of the 24 participants were UK home students schooled in the UK.

\section{Perceived barriers to performance}

All narratives highlighted students' views on barriers and facilitators to performance during undergraduate medical training. The data were categorised into three main causal themes:

- Importance of relationships: exploring the relationships among students and their peers and among students and staff. This was particularly important as poor relationships affect the learning experience and lead to disengagement, lack of motivation and withdrawal. ${ }^{22}$

- Institution and learning: examining how the students interact with the institution and their learning opportunities, such as factors that may generate limitations and barriers to learning and attainment, for example, patient encounters and poor interactions with clinicians.

- Psychosocial and identity: psychological, societal and cultural factors that affect students' learning experience, engagement and attainment, particularly stereotyping and racism and cultural differences.

Within the three main themes, seven subthemes were identified that were perceived to cause barriers to performance (figure 2).

\section{Relationship with peers: finding allies, isolation and social networks}

Peers and staff were identified as both positive and negative influences on performance. Peers were allies who provided solidarity, as well as academic and emotional support. The majority of participants had a diverse range of friends, however, many noted that their closest friends at medical school were other students from a BME background:

My friendship group mostly consists of people of colour. I don't know if it's something I generally gravitate towards. They are also people who look or dress similarly to me.

\section{Female, Asian Pakistani}

I find that because we're all minorities, you [...] stick together and the more you get to know each other it's like we're actually quite different, but $[\ldots]$ there is no one else that you relate to really, so you just kind of stick with them.

\section{Female, Black African}

Participants explained they were drawn towards finding allies in other ethnic minority students, despite not necessarily having common interests or hobbies. Such alliances helped some students to overcome their feelings of 
A

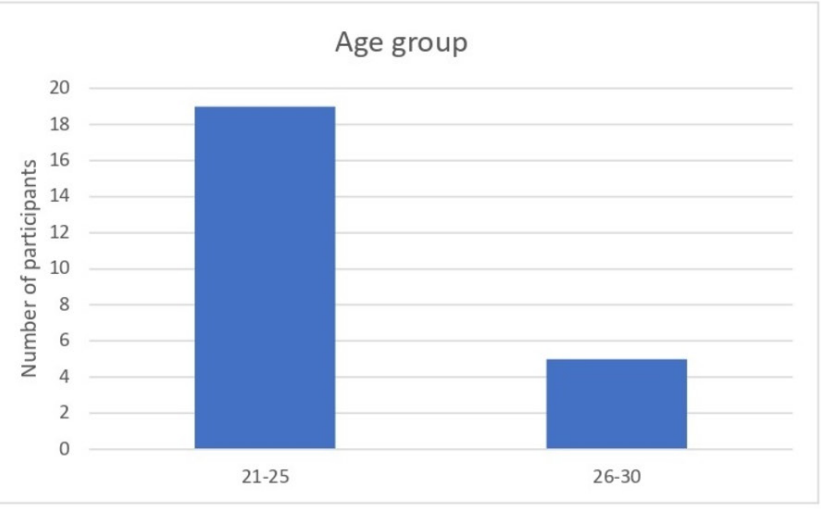

B

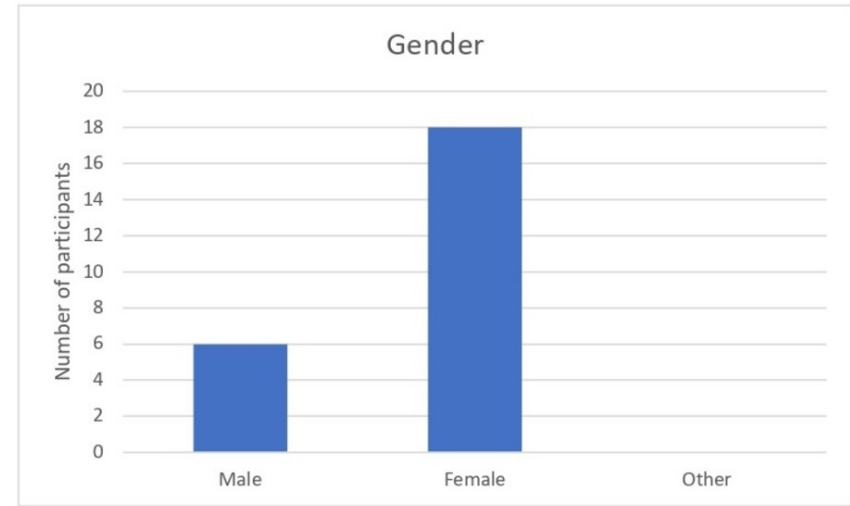

C

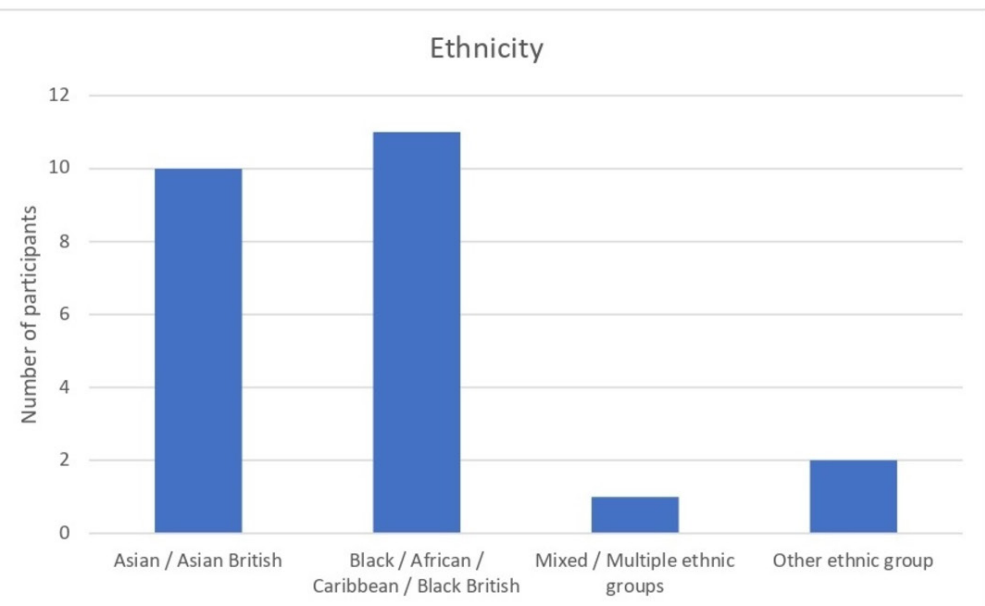

Figure 1 Participant demographics by characteristic. (A) Participants by age group; (B) participants by gender; (C) participants by ethnicity.

isolation and a few students said they gained confidence by having these friendship groups:

where I'm from back home [...] my school was like all ethnic minorities so I was only friends with people that did the same things that I did, like the same things I did, whereas here it's more like you want to stick with people who are similar to you, even though you don't necessarily like the same things, you [stick with them] because you have that common ground; the basis of what you both are is similar so you relate to each other more and than with a [White] person, just because you are an ethnic minority.

Female, Black African

[...] in my first year, in my Friday [group] sessions, I've had no ethnic minorities, so I tend to be by myself

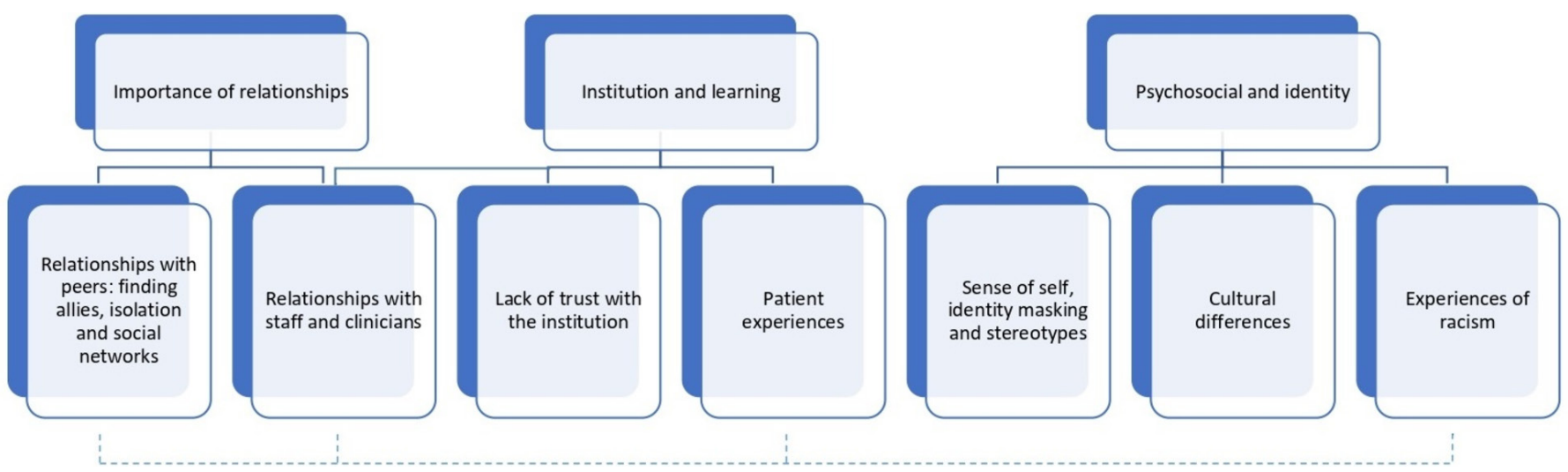

Figure 2 The main themes (top level) and subthemes (bottom level) describing the difficulties faced by BME graduateentry medical students at a West Midlands medical school that were perceived as barriers to performance. The subtheme 'relationships with staff and clinicians' was linked with two main themes 'importance of relationships' and 'institution and learning' as illustrated previously. The subtheme 'experiences of racism' was linked to two subthemes within the main theme 'importance of relationships' and one subtheme in 'institution and learning' as illustrated by the dotted lines. 
just because I didn't feel I had someone, like an ally [...] but this year, it's like I have a few more people $[\ldots]$ and it kind of gives you a boost $[\ldots]$

Female, Black African

Many also remarked they felt more comfortable among other ethnic minorities as they shared a common understanding, specifically, in appreciating cultural differences and acknowledging bias or discrimination often encountered by minority groups:

I'm not really sure how to explain it but $[\ldots]$ there are certain things I may have faced in my life, which other ethnic minorities would understand and those who aren't an ethnic minority wouldn't really get because it's not something they've experienced. Maybe it's something they've heard about but not necessarily something they've felt themselves.

\section{Female, Black Caribbean}

Most BME students reported feeling isolated, explaining that each cohort consisted of predominantly white students. Students felt that they were not represented within the student body. Many who came from multicultural cities such as London and Birmingham found it difficult to adapt and struggled to fit in what they perceived to be a predominantly white student population. Many participants also reported that they did not feel 'good enough' to be at medical school:

[...] I constantly feel like I don't deserve to be here [...] a lot of the time I feel so different [...] I have that constant feeling that I don't deserve to be here $[\ldots]$ because I don't fit in with what your typical medic does or what their background is [...]

\section{Female, Black African}

[...]I did feel a little bit lesser than my non-ethnic minority counterparts. I felt like, oh maybe, I don't deserve to be here as much as they do [...] It was something that played on my mind a little bit.

\section{Female, Black Caribbean}

Several students felt a sense of invisibility among their white peers as they commented that many white peers confused them with other ethnic minority students. Additionally, participants explained that many white students often did not learn the correct pronunciation of their names, often trying to shorten or anglicise it without their permission. Many found this very frustrating and impeding to building new relationships with their peers:

Yeah, I'm not sure when people are talking to me if they know who they're actually talking to

\section{Female, Asian Indian}

I just hate it so much because like my name is, it's not even hard. It's literally, you say it the way it's spelt but no one can get it. I feel like no one personally makes the effort to get it and it's like I refuse to let them shorter my name until I know you can get it because I feel like, it's just like a basic sign of respect to just get it. It's just so frustrating because it's like, it's not even hard.

Female, Black African

Many participants described the importance of using social networks to increase academic performance highlighting that social networks provided access to clinical learning opportunities as well as a number of learning resources. Both were regarded as essential to learning and increasing performance. Students remarked that they felt disadvantaged as they were less likely to acquire resources available to their white counterparts that facilitated learning and achievement:

It does make a huge difference. It's sad but it does make a difference $[\ldots]$ having those links, those connections, being in the right Facebook groups [...] helped me a lot.

Female, Black African

I've never been someone to really heavily depend on friends when it comes to like exams or whatever, but I've realised since starting med school if I didn't have friends with me, I probably would not be in this position.

Female, Asian Indian

If you're not in the right friendship groups or Facebook groups, you've got less access to peer resources $[\ldots]$ Being BME and isolated, you're more likely to be disadvantaged.

Female, Black African

\section{Relationship with staff and clinicians}

Relationships with medical school staff and clinicians were perceived as important to learning and performance. At best, clinicians developed students' knowledge, clinical skills and confidence by providing extra learning opportunities and giving constructive feedback. Participants reported that overall, they received good teaching from clinical staff, though, all said that they noted a better experience with clinicians from BME backgrounds:

I've had bedside teaching from a member of staff who is from a similar background to me. I think sometimes if they are from a similar background, they work you harder and they are more critical, which is good as it's more helpful. They have a higher expectation of you as they set the bar slightly higher which is interesting.

Female, Asian Pakistani

I find it quite the opposite because most of the senior Consultants at the hospital are Asian men and they are very paternal towards me which I'm very grateful for. Like if that's the only privilege I had, then I'm taking it. So, they've been very nice, they've been very nurturing, they've given me all the attention I need 
which is a lot. $[\ldots]$ they've been praising me [...] which has been motivating and you feel less other in the hospital setting.

\section{Female, Asian Bangladeshi}

In contrast, many participants felt that most staff based in the medical school did not appreciate the cultural differences among students, reporting that several lecturers made culturally insensitive or inappropriate comments. Some students said that more effort should be made to ensure staff members were culturally trained, though, one participant felt cultural training would not suffice to fully understand the challenges they faced:

$[\ldots]$ as much as you want to say cultural training will make a difference, unless you're from an ethnic minority background, $[. .$.$] you're not gonna empathise$ with the situations.

\section{Female, Asian Bangladeshi}

Also highlighted was the lack of BME representation among medical school staff. Representation was considered important as many felt isolated among their peers. One participant said they were less likely to report difficulties or seek support from medical school staff due to the lack of BME staff:

More representation is needed, not just Black [lecturers] but Asian and Arab as well. I think that would be quite good.

\section{Female, Black African}

At the medical school [...] there's not enough people in the echelons of the faculty staff who [...] I can relate to, so I don't think there's anyone necessarily that I would go for support [...]

Female, Asian Bangladeshi

\section{Lack of trust with the institution}

Many participants felt that the institution did not appreciate or understand the challenges they faced throughout their undergraduate career. Students were not clear on the procedures for reporting racial incidents or concerns and none were able to identify a specific member of staff who they felt confident in investigating such matters. This lack of structural guidance was often perceived as the medical school not caring about the difficulties faced by BME students and so students were less likely to report any incidents to the institution:

It's again - what's going to be done about it? And then it's kind of like it's a word of mouth type thing so ok, I've said that this person has said this, but ok you then talk to that person and the person says no I didn't say that, I said something else and then what?

\section{Female, Black Caribbean}

[...] so conversations I've had with other people of ethnic minority backgrounds is that they feel like faculty staff here, don't have enough cultural training either so they won't really understand the impact of say the n-word or other statements which have been made towards ethnic minority students or about ethnic minority students. So, they are not [going to], or they won't be able to support us in that way basically.

Female, Asian Bangladeshi

\section{Patient experiences}

Experiences with patients were perceived as facilitators to learning as students were able to apply their theoretical knowledge to clinical practice. Participants reported that most patients were open to BME students practising their clinical skills with them. In contrast, some patient experiences were perceived as impeding learning and performance as they dented students' confidence and exposed them to biases. Overt racism was occasionally reported by participants and many reported experiencing microaggressions as well as witnessing microaggressions against others:

So, the first ever patient I spoke to at med school was an elderly female and she wouldn't talk to me because I was "foreign". Erm, which was really embarrassing because I was asking her questions from a pro forma that we were given and she was telling me that I was being offensive to her [...] and she made such a big massive palaver about it and then when my White male colleague went and spoke to her, she was happy as Larry, answering all questions even though they were exactly word for word the same questions that I was asking [...] I [then] went home that day and cried because I thought that's what my experience of medicine is going to be throughout my career.

Female, Asian Bangladeshi

I was at a hospital on a ward where there were a lot of older White patients and I took about three histories and every one of those patients asked me where I was really from. I then had to explain to them that I was born here and they were like "wow, you were really born here" and then it got to the point where I joked with one of the patients and told them that I was born in my parents' home country and my mother gave birth to me in a hut. I was so angry and fed up of having to explain that I'm from here.

\section{Female, Black African}

Last year, a patient said "I passed for White" [...] They said it in a way where they thought they came across positive - like being White is positive. Erm, and it's only when they heard my name, they were like "Oh" [...] then they automatically linked me to a certain religion. [...] I was shocked.

Male, Asian Pakistani

Sense of self, identity masking and stereotypes

Most participants described having to change or hide their natural personalities in order to conform to the 
social groups at medical school. As participants felt that each cohort predominantly consisted of white students, there was a sense of responsibility among BME students to represent their ethnic group in a positive light. They also commented on the perceived need to monitor and moderate their accents, their expression of emotions and the content of their speech:

[...] you feel like they're going to base all of their opinions on you, so sometimes you have to sort of water down some of the opinions you have or $[\ldots]$ you have to kind of force yourself to make yourself more agreeable to people just because you're aware that $[\ldots]$ they are basing their opinion of Muslim people on me $[\ldots]$

Female, Asian Bangladeshi

You just $[\ldots]$ don't know how people are going to take you $[\ldots]$ a lot of the time it is like $[\ldots]$ you're the voice of the people $[\ldots]$ so what they see with you is what they want [to] assume for everyone and it might be that they've met someone else that is like you, [and] maybe they didn't have a good experience. I don't want to create something that'll cause them to think oh this is how [...] Black people are.

\section{Female, Black African}

Many students talked about the pressure of knowing that they may be subject to negative stereotyping, whereby overgeneralised negative beliefs about their ethnic group may be applied to them. One student explained that she actively tried to avoid negative stereotyping. Some students said they were subject to stereotyping and remarked that incorrect assumptions were frequently made about them. Participants reported that wrong assumptions negatively affected their relationships with peers and staff, implying that stereotyping could impede good educational relationships with peers and medical school staff:

Also, I found someone here described me as intimidating which [...] throughout my entire life, I've never been called intimidating, people would say that I'm soft [...] until I came here, I've never been called intimidating.

Female, Black Caribbean

That's actually one of my biggest fears because I know myself. I'm not intimidating but I know that people tend to [label you as intimidating] when you're passionate $[\ldots]$ so I always try to be extra nice just to avoid that because I think it's quite hurtful to call someone intimidating.

\section{Female, Black African}

I think especially as a woman from an ethnic background, if you're vocal, if you're passionate, [...], you can be sort of labelled as aggressive or intimidating.

Female, Black Caribbean
Even though BME students recognised that they may be subject to stereotyping, several remarked that there was little they could do to either influence or change the biases or discrimination which they may face.

A few participants highlighted the common misperception of South Asian medical students, particularly those of Indian heritage, often held by clinicians and the public. Students stated that people assumed that their choice to study medicine was to conform to their parents' wishes rather than internal motivation and they were not sure whether such perceptions had affected their performance but acknowledged that this was a stereotype that they frequently thought about and tried to dissociate with:

'Cause you're Asian, people [are] like you're doing Medicine because your parents forced you to.

Female, Asian Indian

I don't know if I'd say it's affected my performance but it's something you feel like you have to defend. Like "Oh no, I actually want to do it" as opposed to my parents have sent me here. It's not how it works.

Female, Asian Indian

\section{Cultural differences}

Cultural differences added to BME students' sense of alienation with several describing how important culture is to their sense of identity:

[...] just as much as I take pride in the fact that I was born here $[\ldots]$, educated here, worked here, [...] made friends here, studying here, will be successful here, at the same time I have connections to other parts of the world and that connection is a part of the reason why I have this identity $[\ldots]$

Male, Arab

Cultural differences may also hinder relationships with their peers as BME students often encountered different social experiences with their white counterparts. Many participants reported that medical school social events were not environments in which they felt comfortable in and therefore were less likely to socialise with their peers:

I often find that the social events are often held in settings that I don't feel comfortable in because I don't drink alcohol and the majority of the medical school culture is often associated with alcohol. I wish that more events were more inclusive.

Female, Black African

[...] you wanna make friends and like if everybody is going out, [or] doing something that you don't really feel hundred percent [about doing], you can't like get involved $[\ldots]$ to the max, it does kind of feel a little bit isolating $[\ldots]$

Female, Black African 


\section{Experiences of racism}

As evidenced throughout the narratives described previously, many BME students commonly experienced racism throughout their undergraduate training. Reports of overt racism were rare but nonetheless occurred. More common however were daily experiences of microaggressions which impacted on their overall student experiences and lowered their self-confidence:

[...] one particular member of that [CBL] group [...] always undermined what I said. I don't know why, maybe he felt I wasn't as well-spoken, but I did get the impression that he didn't believe me because I'm of a different background to him or a different colour to him. For example, if I answered a question, he would totally disregard what I would say but then someone who was of the same colour as him would repeat the exact same thing as I said 2 min later and then he'll be "yes, yes, I agree with you”. Another example would be, he would constantly check things, go on the internet, to see if I'm correct and I found that quite disheartening because he would only do this to me or my other classmate who was of colour.

Female, Black African

\section{DISCUSSION}

\section{Statement of principal findings}

In this small study of BME students' perspectives on barriers and facilitators to performance, most participants reported barriers that they felt impeded their learning and performance. Relationships with peers were considered important to learning, but participants found it difficult to fit in and felt isolated among their white peers. Difficulties in developing good relationships with peers were perceived to result partly from cultural differences, racism and bias. The perceived small number of BME students in each cohort also added to the difficulty of students forming relationships with their peers. Many participants' narratives indicated that they masked their identity in order to fit in and to avoid negative stereotyping. There was a general lack of trust in the institution's ability to support BME students, which led to some students' reluctance to access medical school support systems. Most students did not seek help from the institution and many looked to their peers for support instead. Students highlighted the need to have clear, structural guidance on matters relating to BME students, such as how to report racial incidents. Relationships with staff and clinicians were also considered crucial to learning and performance. Participants narrated good teaching experiences in clinical environments, especially from clinicians from BME backgrounds. Several participants highlighted the lack of BME representation among medical school staff as well as the lack of cultural awareness. Patient experiences were widely considered as excellent learning opportunities, though at times exposed BME students to racism.

\section{Strengths and weaknesses of the study}

There are several strengths to this qualitative study. It is the first to explore the experiences of $\mathrm{BME}$ graduate-entry medical students. It provides further insights into the causes of the differential attainment gap, building on previous research. ${ }^{2-4}$ 9-12 22-24 The use of a qualitative design elicited in-depth and detailed narratives on participants' experiences. The use of focus groups encouraged candid responses and group discussion facilitated recollection and sharing of experiences. Multiple cohorts were also included within this study, which elicited narrated experiences from students in each year of the GEM programme. In this group setting, some participants may have felt inhibited to share personal experiences, while others may have amplified their experiences, and therefore, some sensitive topics may have been under-discussed. The themes which emerged from the data were dependent on the chosen sample, therefore, other themes may have arisen if different or more participants had taken part in the study. Furthermore, it is possible that participants may have had specific reasons for taking part, which could have influenced the themes that arose in the focus groups. The ethnicity and gender of the researcher as well as the researcher's position as a fellow medical student may have affected participants' discussion of certain topics. Participants' perception of the researcher may have aided participants to feel more comfortable in discussing the taboo of ethnicity, ${ }^{25}$ enabling discussion of personal and sensitive topics. On the other hand, some participants may have found it difficult to discuss some topics in greater depth with a fellow student. Although the impact is not quantifiable, and no participant stated that they did not wish to speak further on a subject due to NM's characteristics, it is, nevertheless, a possibility. It is also possible that the researcher's own experiences of medical education may have influenced the interpretation of the data. For most qualitative studies, generalisability is an inherent difficulty. ${ }^{1126}$ As this was a small study of one institution, it is not clear whether these findings would be replicated in other institutions. The aim of this study was not to provide generalisations, but to provide a preliminary exploration of the topic, with a view to promote reflection by academic staff, clinicians, students and other stakeholders, and inform future research. It is important to acknowledge that BME students in this study were not a homogeneous group: as individuals, they had unique identities as well as different ethnic, cultural, socioeconomic and educational backgrounds. This study was not able to examine how these intersect to shape individual students' experiences of medical education. Nevertheless, the intersectionality between ethnicity, gender, education and disability has been shown to shape attainment in medicine. ${ }^{2728}$ 
Strengths and weaknesses in relation to other studies discussing important differences in results

Some of the findings from this study are concordant with those from other studies. The importance of relationships with staff and clinicians noted in this study has been highlighted as a barrier to performance in previous medical education research. ${ }^{23}$ Other studies have also identified that such relationships can be impeded by stereotyping as well as ethnic differences. ${ }^{1124}$ Although there is some evidence to suggest that stereotype threat impedes the performance of ethnic minority students, ${ }^{11} 24$ it has been relatively understudied in undergraduate medical education. Other studies have also identified that medical students tend to seek friendships and support from others in their own cultural group. ${ }^{249}$ Social networks and social capital in medical education have also been linked to student attainment and put forward as possible reasons for the attainment gap. ${ }^{2324} 29$ Although social networks based on ethnicity were noted in this study, participants also sought support from others in the wider BME group. The finding that most BME students described the need to find allies among other BME students which led to relationships that would not necessarily have occurred in other settings has not been identified in previous studies. These differences could be due to the small numbers of specific ethnic groups within each cohort at this West Midlands medical school but, nevertheless, raise issues about the availability of support for BME students in cohorts with relatively small numbers of BME students. The finding that learning resources were not always shared with BME students by their white counterparts has been found in a study of students on a 5-year programme. ${ }^{24}$ Students who were excluded from or exclude themselves from social networks with high levels of social capital missed out on resources important for success and attainment in medicine, particularly resources passed on from academics, clinicians and high achieving students. Racism, including microaggressions, in international medical schools is well known ${ }^{30-32}$ but previous research has not, to the best of our knowledge, considered the effects on UK BME medical students and their performance. Other studies have shown that individuals who experience racial microaggressions are more likely to exhibit negative mental health symptoms, ${ }^{33}$ suggesting associations between BME students' experiences of racism, their mental health and their successive performance. Identity masking, as reported in this study, is a wellknown psychological phenomenon ${ }^{34-36}$ but it has not been studied in relation to BME students in medical education.

\section{Meaning and possible explanations and implications}

Medical students need an academic environment that will enable them to foster good working relationships with their peers, which can be difficult due to the fastpaced nature of the GEM course. The widespread belief that medical school staff had a lack of cultural awareness does not mean that staff were necessarily discriminatory or biased; however, our findings suggest that more may need to be done to increase awareness of culture, diversity and unconscious bias, as well as implementing anti-racist pedagogy within the medical curriculum. ${ }^{37}$ Increasing BME representation among medical school staff is likely to help students feel more supported and may also improve cultural understanding and tolerance as well as increase self-confidence of BME students. This study also suggests that students felt isolated and looked to their BME peers for support. Homophily, that is, the tendency for people to form friendships with others similar to them may be a possible explanation. ${ }^{24}{ }^{29} \mathrm{It}$ may explain, at least in part, why BME students reported finding allies among other BME students and felt isolated among a large cohort of white medical students, who themselves may be forming friendships with people from similar ethnic groups. Woolf $e t a l^{29}$ have suggested that there may be 'hidden medical schools' when medical students form social networks based on ethnicity and that these can impact on student attainment. The widespread perception in this study that the cohorts were predominately white does not mean that this was indeed the case; however, more could be done to ensure that each cohort comprises of a wide range of students from different socioeconomic, ethnic, cultural and educational backgrounds. The importance of high-quality student support programmes that provide 'safe havens' for students experiencing culturally and socially alienating environments, and that foster social inclusiveness have been identified as key to academic success. ${ }^{38}$ Institutions are in a position to ensure that BME students are well integrated among their peers and need to consider how they can increase opportunities to create friendships among all ethnic groups. Although the responsibility for this lies with the institution, the BME student population and networks could also be important to fostering a sense of community; increasing the awareness of diversity and culture within the medical school. A lack of structural guidance on the procedures for reporting racial incidents or concerns was noted in this study and could dissuade students from seeking student support thus affecting their wellbeing. Guidance on reporting and tackling racism therefore needs to be developed. Furthermore, this and other studies suggest that medical schools should also review their diversity and anti-racism training for staff and students. Kumagai and Lypson ${ }^{39}$ suggest that this should go beyond knowledge competency training to the fostering of a critical awareness of the self and others in relation to racism and other forms of discrimination within healthcare.

\section{Unanswered questions and future research}

Further research is needed to determine the prevalence of the barriers identified in this research at this West Midlands medical school as well as other UK 
GEM courses. The student experiences of UK BME graduate-entry medical students need to be analysed and further researched as they are different in terms of the demographics and life experiences to those on 5-year programmes. Research into medical schools' institutional processes for promoting diversity and critical consciousness among all students needs to be carried out.

\section{CONCLUSIONS}

This is the first study exploring BME students' perspectives on barriers and facilitators to performance on a GEM course in the UK. BME students in this study reported experiencing relationship issues with their peers, academic and clinical staff, lack of trust in the institution and some racist events. Although it is not clear from this study whether these findings would be replicated in other institutions, they nevertheless highlight important issues to be considered by all stakeholders of graduate-entry undergraduate medical education.

Contributors NM: conceived of the research project which was further developed with $\mathrm{MM}$ and $\mathrm{CB}$; analysed the data under the supervision of $\mathrm{MM}$ and $\mathrm{CB}$; wrote the first draft of the article and all authors revised it critically for important intellectual content. NM, CB and MM: designed the research project. NM, with MM and CB: interpreted the data. NM and CB: revised the draft paper. All authors approved of the final version to be published. NM is the guarantor.

Funding The authors have not declared a specific grant for this research from any funding agency in the public, commercial or not-for-profit sectors.

Competing interests None declared.

Patient consent for publication Not required.

Ethical approval Ethical approval was granted by The University of Warwick Biomedical and Scientific Research Ethics Committee August 2018 (REG0-2018-2244).

Provenance and peer review Not commissioned; externally peer reviewed.

Data availability statement All data relevant to the study are included in the article or uploaded as supplementary information.

Open access This is an open access article distributed in accordance with the Creative Commons Attribution Non Commercial (CC BY-NC 4.0) license, which permits others to distribute, remix, adapt, build upon this work non-commercially, and license their derivative works on different terms, provided the original work is properly cited, appropriate credit is given, any changes made indicated, and the use is non-commercial. See: http://creativecommons.org/licenses/by-nc/4.0/.

\section{ORCID iD}

Nariell Morrison http://orcid.org/0000-0001-6961-0032

\section{REFERENCES}

1 Universities UK and the National Union of Students. Black, Asian and Minority Ethnic student attainment at UK universities: \#ClosingTheGap, 2019. Universities UK. Available: https://www. universitiesuk.ac.uk/policy-and-analysis/reports/Documents/2019/ bame-student-attainment-uk-universities-closing-the-gap.pdf [Accessed 1st May 2019].

2 McManus IC, Richards P, Winder BC, et al. Final examination performance of medical students from ethnic minorities. Med Educ 1996;30:195-200.

3 Woolf K, McManus IC, Potts HWW, et al. The mediators of minority ethnic underperformance in final medical school examinations. $\mathrm{Br} \mathrm{J}$ Educ Psychol 2013;83:135-59.

4 Woolf K, Potts HWW, McManus IC. Ethnicity and academic performance in UK trained doctors and medical students: systematic review and meta-analysis. BMJ 2011;342:d901.
5 Xu G, Veloski JJ, Hojat M, et al. Longitudinal comparison of the academic performances of Asian-American and white medical students. Acad Med 1993;68:82-6.

6 Stegers-Jager KM, Steyerberg EW, Cohen-Schotanus J, et al. Ethnic disparities in undergraduate pre-clinical and clinical performance. Med Educ 2012;46:575-85.

7 Wass V, Roberts C, Hoogenboom R. Effect of ethnicity on performance in a final objective structured clinical examination: qualitative and quantitative study. BMJ 2003;326:800-3.

8 Esmail A, Roberts C. Academic performance of ethnic minority candidates and discrimination in the MRCGP examinations between 2010 and 2012: analysis of data. BMJ 2013;347:f5662.

9 Haq I, Higham J, Morris R, et al. Effect of ethnicity and gender on performance in undergraduate medical examinations. Med Educ 2005;39:1126-8.

10 Regan de Bere SN, Nasser M. Understanding differential attainment across medical training pathways: a rapid review of the literature. final report prepared for the general medical Council. Plymouth University, 2015. Available: http://www.gmc-uk.org/GMC Understanding_Differential_Attainment.pdf_63533431.pdf [Accessed 2nd February 2018].

11 Woolf K, Cave J, Greenhalgh T, et al. Ethnic stereotypes and the underachievement of UK medical students from ethnic minorities: qualitative study. BMJ 2008;337:a1220.

12 Cardiff University. independent review panel into issues of racial equality in the school of medicine, Cardiff University, 2017. Available: www.cardiff.ac.uk/_data/assets/pdf_file/0011/551837/Prof-DineshBhugra-report-Final.pdf [Accessed 31st May 2018].

13 Kumwenda B, Cleland J, Greatrix R, et al. Are efforts to attract graduate applicants to UK medical schools effective in increasing the participation of under-represented socioeconomic groups? a national cohort study. BMJ Open 2018;8:e018946.

14 Machado M. Internal MB ChB assessment reports. Warwick Medical School; 2019.

15 Green J, Thorogood N. Qualitative Methods for Health Research. 4th ed. SAGE Publications, 2018.

16 Office of National Statistics. Ethnicity and national identity in England and Wales, 2011. Available: https://www.ons.gov.uk/peoplepopula tionandcommunity/culturalidentity/ethnicity/articles/ethnicityandnati onalidentityinenglandandwales/2012-12-11\#ethnicity-in-englandand-wales [Accessed 26th December 2018].

17 Krueger RA, Casey MA. Focus Groups: A Practical Guide for Applied Research. 5th ed. SAGE Publications, 2015.

18 Braun V, Clarke V. Using thematic analysis in psychology. Qual Res Psychol 2006;3:77-101.

19 Maguire M, Delahunt B. Doing a thematic analysis: a practical, step-by-step guide for learning and teaching scholars. AISHE-J: The All Ireland Journal of Teaching \& Learning in Higher Education 2017;9:3351-14.

20 QSR International Pty Ltd. NVivo Version 12: QSR International Pty Ltd, 2018.

21 O'Brien BC, Harris IB, Beckman TJ, et al. Standards for reporting qualitative research: a synthesis of recommendations. Acad Med 2014;89:1245-51.

22 Mountford-Zimdars A, Sabri D, Moore J. Causes of differences in student outcomes. Higher Education Funding Council for England, 2015.

23 Woolf K, Rich A, Viney R, et al. Perceived causes of differential attainment in UK postgraduate medical training: a national qualitative study. BMJ Open 2016;6:e013429.

24 Vaughan S, Sanders T, Crossley N, et al. Bridging the gap: the roles of social capital and ethnicity in medical student achievement. Med Educ 2015;49:114-23.

25 Roberts JH, Sanders T, Wass V. Students' perceptions of race, ethnicity and culture at two UK medical schools: a qualitative study. Med Educ 2008;42:45-52.

26 Holloway I, Galvin K. Qualitative Research in Nursing and Healthcare. 4th ed. Wiley-Blackwell, 2016.

27 Asghar ZB, Siriwardena AN, Elfes C, et al. Performance of candidates disclosing dyslexia with other candidates in a UK medical licensing examination: cross-sectional study. Postgrad Med J 2018;94:198-203.

28 Kumwenda B, Cleland JA, Walker K, et al. The relationship between school type and academic performance at medical school: a national, multi-cohort study. BMJ Open 2017;7:e016291.

29 Woolf K, Potts HWW, Patel S, et al. The hidden medical school: a longitudinal study of how social networks form, and how they relate to academic performance. Med Teach 2012;34:577-86.

30 Beagan BL. 'Is this worth getting into a big fuss over?' everyday racism in medical school. Med Educ 2003;37:852-60. 
31 Robb N. Racism can rear its ugly head at medical school, study finds. Can Med Assoc J 1998;159:66-7.

32 Sue DW, Capodilupo CM, Torino GC, et al. Racial microaggressions in everyday life: implications for clinical practice. Am Psychol 2007;62:271-86.

33 Nadal KL, Griffin KE, Wong Y, et al. The impact of racial Microaggressions on mental health: counseling implications for clients of color. J Couns Dev 2014;92:57-66.

34 Davis TL. Gender differences in masking negative emotions: ability or motivation? Dev Psychol 1995;31:660-7.

35 Matsumoto D, Yoo SH, Nakagawa S, et al. Culture, emotion regulation, and adjustment. J Pers Soc Psychol 2008;94:925-37.
36 Matsunaga M. Shaping, masking, and unmasking of a stigmatized identity: the case of Japan-residing Koreans. Howard J Commun 2007;18:221-38.

37 Ahmad NJ, Shi M. The need for Anti-Racism training in medical school curricula. Acad Med 2017;92:1073.

38 Curtis E, Wikaire E, Kool B, et al. What helps and hinders Indigenous student success in higher education health programmes: a qualitative study using the critical incident technique. High Educ Res Dev 2015;34:486-500.

39 Kumagai AK, Lypson ML. Beyond cultural competence: critical consciousness, social justice, and multicultural education. Acad Med 2009;84:782-7. 